\title{
PREPARATION AND EVALUATION OF DEEP CLEANSING EXFOLIATOR
}

\author{
FATIMA GRACE X, ANBARASAN B, KANIMOZHI T, SHANMUGANATHAN S*
}

Department of Pharmaceutics, Faculty of Pharmacy, Sri Ramachandra Medical College and Research Institute, Porur, Chennai - 600 116, Tamil Nadu, India. Email: shanmugganathan@gmail.com

Received: 10 March 2018, Revised and Accepted: 16 April 2018

ABSTRACT

Objectives: The objective of the present study is to formulate an exfoliant using natural ingredients along with diatoms. Skin care products are important factor to improve confidence in individuals. Health of an individual is mainly represented by skin which is the major part of the body. Skin can be affected by several environmental factors such as ultraviolet rays, pollution, dust, and climatic changes that can intensify issues related to skin. Environmental causes can be prevented from skin damage by treating with topical application of synthetic or herbal cosmetics.

Methods: In this preparation, diatoms are used, derived from marine phytoplankton which may contain a small quantity of muddy sludge, sand, and debris. Other natural ingredients are kiwi fruit, almond, and coffee seeds. Esthetic ingredients used in this preparation include pH modifiers, viscolysers, and surfactants. Among these ingredients, diatoms and coffee seeds attribute to the exfoliating activity of the preparation.

Results: The prepared gel was evaluated for various parameters such as color, odor, consistency, pH, viscosity, spreadability, washability, grittiness, foamability, irritability, and extrudability. The results were found to be satisfactory.

Conclusion: The present work was attempted to make a herbal exfoliant using suitable base to form a gel. Since diatoms are natural exfoliating agent, they are incorporated into the formulation which increases the efficiency of the product. Various parameters have been evaluated providing satisfactory result and improve the appearance of the skin without any side effects.

Keywords: Exfoliant, Diatoms, Coffee seeds, Kiwi, Almond, Gel.

(C) 2018 The Authors. Published by Innovare Academic Sciences Pvt Ltd. This is an open access article under the CC BY license (http://creativecommons. org/licenses/by/4. 0/) DOI: http://dx.doi.org/10.22159/ajpcr.2018.v11i7.25807

\section{INTRODUCTION}

From ancient period, plants have been the basis for medical treatment and such traditional medicine is practiced even today. It is estimated that $80 \%$ of the people worldwide rely on herbal medicines derived from natural source [1]. This is because it is cheap and consumers also believe that herbal medicines are safe and are derived from nature. Apart from curing ailments, it can also be used for beautifying purpose, and thus, the usage of natural cosmetics has been increased and is high in demand. The word cosmetics is derived from Greek word "kosmos" defined as articles intended to be rubbed, poured, sprinkled or sprayed, or introduced into or otherwise applied to human body or any part for cleansing, beautifying, promoting attractiveness, or altering appearances. Skin is the body's largest organ, the first line of defense, and accounts for more than $10 \%$ of body mass [2]. It provides protection, water preservation, lubrication, and regulates temperature. Exposure of skin to chemical agents, radiation, mechanical trauma, and biological agent such as parasites and microorganism provides dull and lifeless skin and also reduces glossiness but sometimes leads to itching, pain, redness, swelling, etc. Exposure of skin to external agent can be prevented by applying topical agents directly on the skin. Formulations such as face pack, face cream, suntan cream, and face exfoliant are prepared by incorporating suitable base [3].

\section{Exfoliant}

Exfoliating agents are those used to remove dead cells present on the skin and boost blood circulation, giving renewed and glowing skin. It keeps face free from dirt, grime, and oils which are also beneficial in keeping the skin pores clean. There are two ways to exfoliate the skin [4,5].

\section{Physical exfoliation}

Abrasive agents are used to remove dead cells by gently rubbing the skin in circular motion with hand or by rough sponge.

\section{Chemical exfoliation}

Chemically dissolves the initial glue that holds dead (keratinized) skin cells together and then penetrates the upper layer of the skin for complete removal of dead cells.

\section{Benefits of using an exfoliant}

1. Helps removing dirt and grime

2. Prevents spots and provide clear complexion

3. Cleans skin before shaving, removes dead skin cells that clog up razor and improve shaving [6].

Ideal properties of an exfoliant

1. Non-toxic

2. Possess small gritty particles

3. Mild abrasive

4. Non-irritant

5. Non-sticky

6. Removes dead skin [7].

Precautions to be taken while applying an exfoliant

1. An exfoliant is selected based on the skin type

2. Excessive exfoliating and rubbing can damage the skin

3. Do not exfoliate skin if any open wounds, cuts, and sunburns present

4. Apply twice a week

5. Apply with a rotating motion to face and neck for about 30 secs. Thoroughly rinse with water $[8,9]$ (Table 1 ).

\section{METHODS}

Materials required for preparing exfoliant were purchased from the local market and local distributors. Diatoms were purchased from Alfa Aesar, Chennai. 


\section{Purification of diatoms}

Diatoms are derived from marine phytoplankton which may contain a small quantity of muddy sludge, sand, and debris. It should be cleaned properly to remove all impurities. $5 \mathrm{~g}$ of diatoms was taken, and it was treated with $15 \mathrm{ml}$ sulfuric acid and $5 \mathrm{ml}$ nitric acid in the ratio 3:1 (mineral acid treatment) into a $1000 \mathrm{ml}$ beaker and $900 \mathrm{ml}$ of water was added. Water was changed for 5 days by removing the supernatant liquid at the top without disturbing the pellets formed below the bottom of the beaker. $\mathrm{pH}$ of the diatoms was noted as neutral using $\mathrm{pH}$ paper [14].

\section{Optical microscopy}

Dispersion of diatoms was characterized by optical microscopy, and its size, shape, and structure morphology can be obtained. Small amounts of purified diatoms were spread on a clean glass slide and examined for its outer structure using light microscope with various magnifications (10× and 40×), and photomicrographs were obtained (Fig. 1) [15].

\section{Preparation of extract}

Kiwi fruit and almond were weighed, and hydroalcoholic extracts were prepared in the ratio 7:3 by maceration. It was then filtered using muslin cloth. The filtrate was collected and is allowed to evaporate in evaporating pan until the desired concentration of extract was obtained. Coffee seed was powdered and was passed using mesh number 30 [16].

\section{Preparation of Gel}

Required quantity of water was taken in a beaker, to which weighed quantity of citric acid, propylene glycol, and sodium lauryl sulfate was added and dissolved. A weighed quantity of carbopol 940 was added little by little in a homogenizer until uniform gel was obtained. To this, extract of kiwi, almond, and coffee powder was added and triturated well, and at last, triethanolamine was added to adjust the $\mathrm{pH}[17,18]$ (Fig. 2)

\section{Direction to use}

Massage the exfoliant gently on to a damp or wet skin in circular motion. Rinse thoroughly with lukewarm water.
Fourier-transform infrared (FTIR) spectroscopy

Samples of diatoms were mixed with $\mathrm{KBr}$ in the ratio $1: 3$ and were pressed as pellet mechanically. The formulated exfoliant was lyophilized which was taken for studying IR analysis using attenuated total reflectance. The spectrum scanning range was from 400 to $4000 / \mathrm{cmand}$ the resolution was $1 / \mathrm{cm}$.

FTIR spectrum of Fig. 3a represents the characteristic peak of diatoms at wave number $1054 / \mathrm{cm}$ confirmed the presence sulfuroxygen containing compounds. Fig. $3 \mathrm{~b}$ shows the characteristic peak of formulated exfoliant at wave number $3312 / \mathrm{cm}$ indicating the presence of (OH group) stretching vibrations. The characteristic peak at $2929 / \mathrm{cm}$ showed $\mathrm{C}=\mathrm{H}$ stretching vibrations. The characteristic peak at $1704 / \mathrm{cm}$ showed $\mathrm{C}=0$ stretching vibrations. The characteristic peak at $1036 / \mathrm{cm}$ showed confirmation of (-S-0) sulfur-oxygen containing compounds. On the whole, diatoms and exfoliant do not show any intermolecular interaction [19].

\section{Evaluation of polyherbal exfoliant [20-23]}

\section{Physical evaluation}

The developed exfoliant was inspected for its homogeneity, color, syneresis, and presence of lumps by visual inspection after it has been set in the container. The color was found to be brown with characteristic odor. The gel showed good homogeneity with the absence of lumps and syneresis.

\section{pH}

The $\mathrm{pH}$ of the gels was determined using digital $\mathrm{pH}$ meter. The $\mathrm{pH}$ value of the exfoliant was 7.4 which is considered acceptable to avoid the risk of irritation on application to the skin.

\section{Spreadability}

The spreadability is very much important as shows the behavior of gel that comes out from the tube. It is used to identify the extent of spreadability by the gel on the skin. A small quantity of sample was

Table 1: Formulation of polyherbal exfoliant [10-13]

\begin{tabular}{|c|c|c|c|c|}
\hline Ingredients & Parts used & Botanical name & Category & Quantity (g/ml) \\
\hline Ethanolic extract of kiwi fruit & Fruits & Actinidia deliciosa & Antiaging, antioxidant, antibacterial & $2 \mathrm{~g}$ \\
\hline Ethanolic extract of almond & seeds & Prunus arabica & Improve skin complexion & $5 \mathrm{~g}$ \\
\hline Diatoms & - & - & Exfoliate skin & $2 \mathrm{~g}$ \\
\hline Carbopol 940 & - & - & Gelling agent & $3 \mathrm{~g}$ \\
\hline Citric acid & - & - & Preservative & $1 \mathrm{~g}$ \\
\hline Triethanolamine & - & - & Neutralizer & Q.S. \\
\hline Propylene glycol & - & - & Moisturizer & $30 \mathrm{ml}$ \\
\hline Sodium lauryl sulfate & - & - & Foaming agent & $0.5 \mathrm{~g}$ \\
\hline Distilled water & - & - & Vehicle & Q.S to $100 \mathrm{ml}$ \\
\hline
\end{tabular}




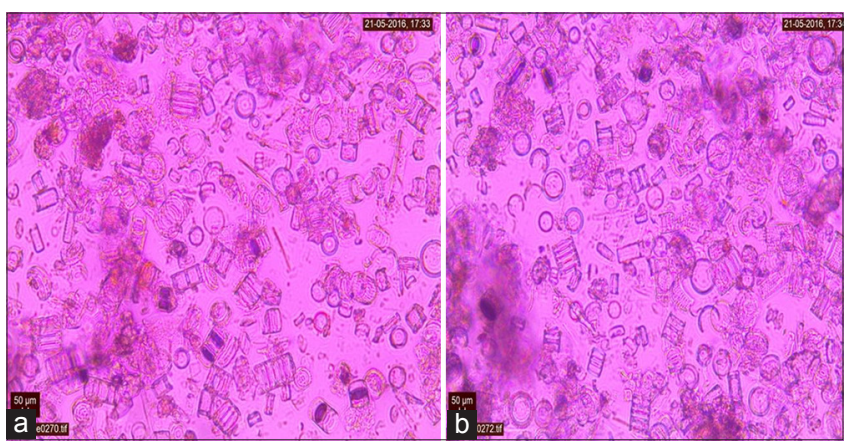

Fig. 1: (a and b) Different shapes of diatoms, especially round, spherical, cylindrical with mesh type of structures

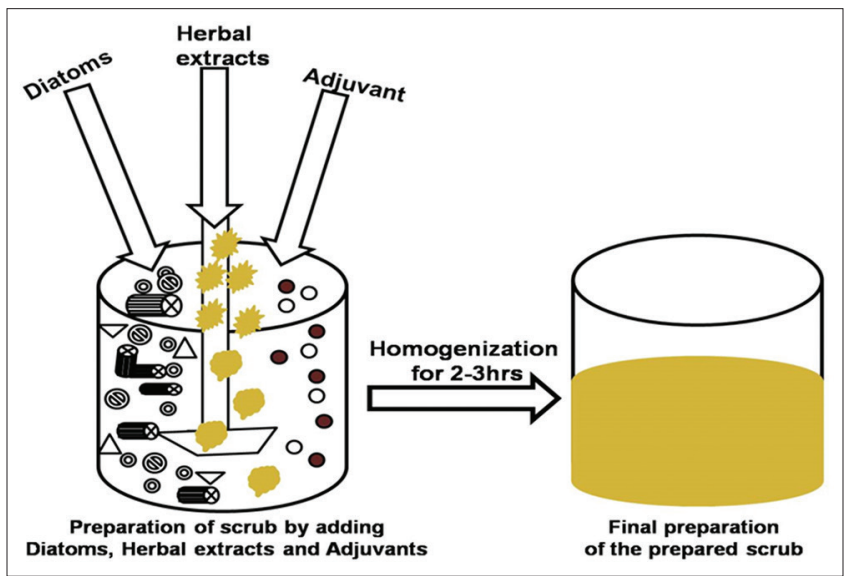

Fig. 2: Diagrammatic representation of the exfoliator

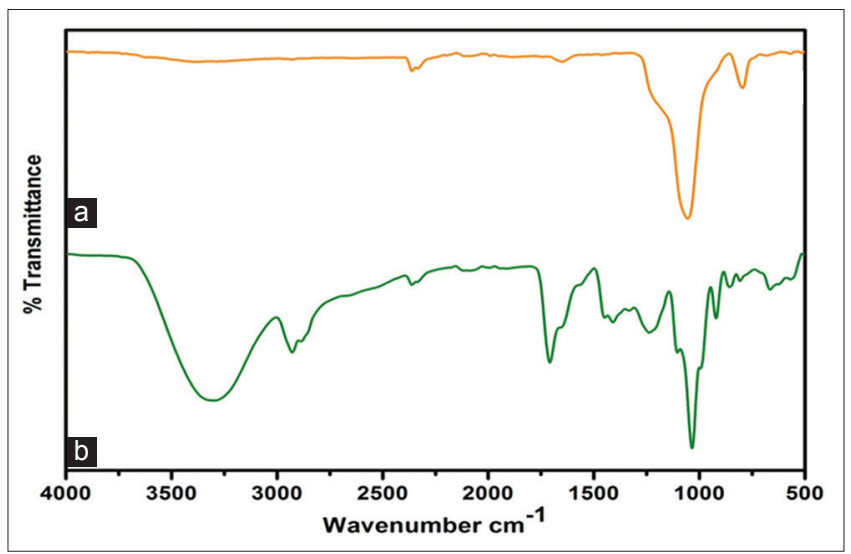

Fig 3: (a) Fourier-transform infrared (FTIR) spectrum of purified diatoms. (b) FTIR spectrum of formulated gel as exfoliant

placed on a glass slide and another slide was placed above them; $100 \mathrm{~g}$ of weight was placed on the slide. The time taken for the gel to spread on the slide was noted and measured which was found to be $6.5 \mathrm{~cm}$ in $5 \mathrm{~min}$. It was calculated using the following formula:

$\mathrm{S}=\mathrm{m} \times \frac{1}{\mathrm{t}}$

S=Spreadability

$\mathrm{m}=$ Weight placed on the slide

l=Length of the glass slide

$\mathrm{t}=$ Time taken in seconds

\section{Extrudability}

To determine extrudability, a closed collapsible tube containing formulation was pressed firmly at the crimped end. When the cap was removed,

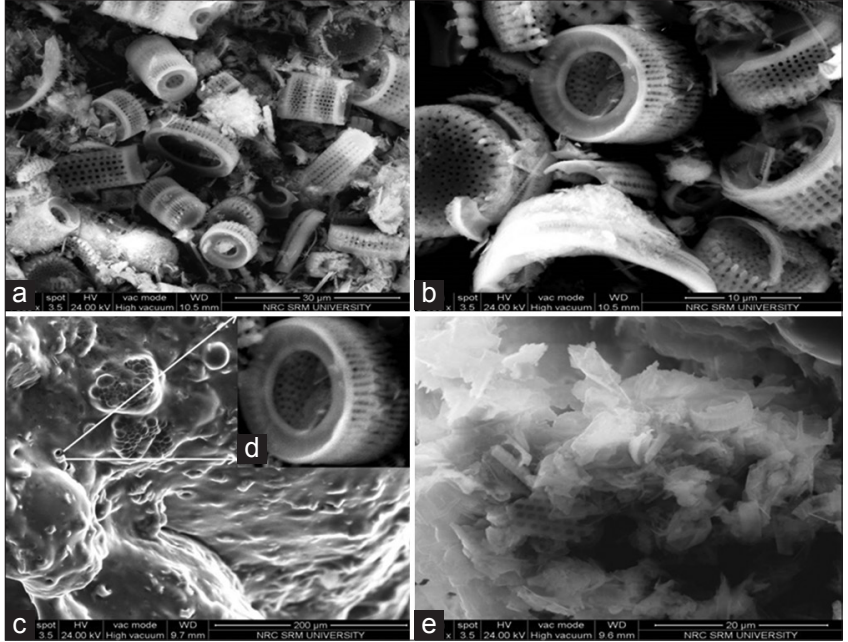

Fig. 4: (a and b) outer morphology of the purified diatoms at different magnification, (c) image of formulated exfoliant in low magnification, (d) cylindrical diatoms embedded in the gel and its outer morphology, (e) image of diatoms adhered along with carbopol

Table 2: Evaluation of poly herbal exfoliant

\begin{tabular}{lll}
\hline Sl. No & Parameters & Observations \\
\hline 1 & Color & Brown \\
2 & Odor & Characteristic \\
3 & Consistency & Good \\
4 & $\mathrm{pH}$ & $7.4 \pm 0.8$ \\
5 & Viscosity & $1050 \pm 0.2$ centipoise \\
6 & Spreadability & $6.5 \pm 0.6 \mathrm{~cm}$ \\
7 & Washability & Easily washable \\
8 & Grittiness & Presence of gritty particles \\
9 & Foamability & Good \\
10 & Irritability & Non-irritant \\
11 & Extrudability & $15.3 \pm 1.2 \mathrm{~g} / \mathrm{cm}^{2}$ \\
\hline Values are reported as three evaluations of mean \pm standard deviation; $\mathrm{n}=3$
\end{tabular}

formulation extruded until the pressure dissipated. Weight in grams required to extrude a $0.5 \mathrm{~cm}$ ribbon of the formulation in $10 \mathrm{~s}$ was determined. The average extrusion pressure in g was reported. It was found to be $15.3 \mathrm{~g} / \mathrm{cm}^{2}$.

\section{Viscosity}

The viscosity of the different gel formulae was determined at $25^{\circ} \mathrm{C}$ using Brook field viscometer DV2T model. The gel sample ( $5 \mathrm{~g}$ ) was placed in the sample holder of the viscometer and allowed to settle for $5 \mathrm{~min}$, and the viscosity measured a rotating speed of $50 \mathrm{rpm}$ at room temperature $\left(25-27^{\circ} \mathrm{C}\right)$. The viscosity was found to be 1050 centipoise.

\section{Irritability}

A small amount of gel was applied externally on the skin surface for few minutes and checked for reactions on the skin. It was found to be non-irritant.

\section{Washability}

Small amount of gel was applied externally on the skin surface, and it was washed with running water. It was found to be easily washable.

Foamability

A small amount of gel was taken in a measuring cylinder, and it was shaken for $5 \mathrm{~min}$ and the foam stability of the gel was measured.

\section{Grittiness}

Exfoliant needs to have abrasive property so to satisfy that the coffee seeds were powdered and passed through sieve no 30 such that the preparation has few gritty particles (Table 2 ). 


\section{Scanning electron microscopy (SEM)}

The particle size of the diatoms was viewed and photographed using SEM. The sample was taken in aluminum stub covered with carbon tape on both the sides. One side was stuck to the stub and other side was to the sample. The instrument JEOL Japan was used to view the diatoms and the exfoliant (Fig. 4).

\section{RESULTS AND DISCUSSION}

Polyherbal exfoliant was prepared and evaluated. It contains ethanolic extract of kiwi fruit and almond which possess antioxidant, antiaging, and skin lightening property. It also contains coffee bean powder acting as a mild abrasive agent in the formulation which additionally has anti-inflammatory activity. Apart from these, diatom is a natural exfoliating agent derived from marine phytoplankton gently soothes the skin surface by releasing dead cell and pore blocking impurities. They can exfoliate the skin without scratching the skin surface by applying pressure on them. Suitable base materials such as gelling agent, preservative, neutralizer, and foaming agent were selected and incorporated into the extract to design a suitable herbal gel. Evaluation parameters such as color, odor, consistency, and $\mathrm{pH}$ were checked. The formulation was found to be slightly alkaline which is compatible with skin, easily spreadable, and non-irritant to the skin.

\section{CONCLUSION}

The present work was attempted to make a herbal exfoliant using suitable base to form a gel. Since diatoms are natural exfoliating agent, they are incorporated into the formulation which increases the efficiency of the product. Various parameters have been evaluated providing satisfactory result and improve the appearance of the skin without any side effects.

\section{ACKNOWLEDGMENT}

The authors are grateful to the management of Sri Ramachandra University for providing all the necessary facilities for the successful completion of the work.

\section{AUTHOR'S CONTRIBUTIONS}

All the authors have contributed equally for the outcome of the present work.

\section{CONFLICTS OF INTEREST}

The authors have no conflicts of interest.

\section{REFERENCES}

1. Shivanand P, Nilam M, Viral D. Herbs play an important role in the field of cosmetics. Int J Pharmatech Res 2010;2 Suppl 1:632-9.
2. Esposito E, Carotta V, Scabbita A, Yalkowsky, Slunick, Stoughton. Cutaneous and transdermal delivery: Processes and systems of delivery. In: Baker GS, Rhodes C, editors. Modern Pharmaceutics. USA: Marcel Dekker, Inc.; 1996. p. 239-98.

3. Aburjai T, Natsheh FM. Plants used in cosmetics. Phytother Res 2003;17:987-1000

4. Barry BW. Dermatological Formulations. Vol. 18. New York, Basel: Marcel Dekker. Inc.; 1983. p. 96-115.

5. Bissett DL, McBride JF, Bast A, Haenen GR, Doelman CJ. Oxidants and antioxidants state of the art. Am J Med 1991;91 Suppl 3C:2S-13.

6. Sharma PP. Cosmetics Formulation Manufacturing and Quality Control. Lucknow: Vandana Publications Pvt. Ltd.; 195-8, 183-5.

7. Banchhor M, Ashawat MS, Saraf S, Saraf S. Herbal cosmetics: Trends in skin care formulation. Phcog Rev 2009;3:82-9.

8. Hiremath SR. Text Book of Industrial Pharmacy, Drug Delivery Systems and Cosmetics and Herbal Drug Technology. 2nd ed. New Delhi: University Press (India) Ltd.; 2008.

9. Dureja H, Kaushik D, Gupta M, Kumar V, Lather V. Cosmeceuticals: An emerging concept. Indian J Pharm 2005;37:155-9.

10. Shweta KG, Mistry RB, Patel UK, Blessy M, Jain HN. Herbal plants: Used as a cosmetic. J Nat Prod Plant Resour 2011;1 Suppl 1:24-32.

11. Gupta P, Sinha D, Bandopadhyay R. Isolation and screening of marine microalgae Chlorella Sp._Pr1 for anticancer activity. Int J Pharm Pharm Sci 2014;6 Suppl 10:517-9.

12. Bharadwaj S, Gupta GD, Sharma VK. Topical gel: A novel approach for drug delivery. J Chem Bio Phys Sci 2012;2 Suppl 2:856-67.

13. Aswal A, Kalra M, Rout A. Preparation and evaluation of polyherbal cosmetic cream. Asian Pac J Trop Med 2012; 5:83-88, 1-4.

14. Stidolph SR. A method for cleaning diatom samples and the preparation of select and stewn mounts. Vic Univ Wellington Libr 1982;26 Suppl 1:10-9.

15. Gupta A. Formulation and evaluation of topical gel of diclofenac sodium using different polymers. Drug Invention Today 2010;2 Suppl 5:250-3.

16. Ravi P, Rao NG, Chowdary S. Formulation, evaluation and antiinflammatory activity of topical etoricoxib gel. Asian J Pharm Clin Res 2010;3 Suppl 2:126.

17. Kumar VR, Kumar S. Formulation and evaluation of Mimosa pudica gel. Int J Pharm Pharma Sci 2011;3 Suppl 1:55-7.

18. Sowmya KV, Darsika C, Grace XF, Shanmuganathan S. Formulation and evaluation of poly herbal face wash gel. World J Pharm Pharm Sci 2015;4 Suppl 6:585-8.

19. Colthup NB. Spectra-structure correlations in the infra-red region. J Optical Soc Am 1950;40 Suppl 6:397-400.

20. Bhaskar G, Arshia S, Priyadarshini SR. Formulation and evaluation of topical polyherbal antiacne gels containing Garcinia mangostana and Aloe vera. Phcog Mag 2009;5 Suppl 19:93-9.

21. Yadav N, Yadav R. Preparation and evaluation of herbal face pack. Int J Recent Sci Res 2015;6 Suppl 5:4334-7.

22. Yamini K, Onesimus T. Preparation and evaluation of herbal anti-acne gel. Int J Pharm Bio Sci 2013;4 Suppl 2:956-60

23. Grace XF, Vijetha RJ, Shanmuganathan S, Chamundeeswari D. Preparation and evaluation of herbal face pack. Adv J Pharm Life Sci Res 2014;2 Suppl 3:1-6. 